\title{
Title: Local and global crosstalk among heterochromatin marks drives epigenome patterning in Arabidopsis
}

\author{
Taiko Kim To ${ }^{1,2 *}$, Chikae Yamasaki ${ }^{1,}$ Shoko Oda ${ }^{1}$, Sayaka Tominaga ${ }^{1}$, Akie Kobayashi $^{2}$, \\ Yoshiaki Tarutani ${ }^{2}$, Tetsuji Kakutani ${ }^{1,2 *}$ \\ ${ }^{1}$ Department of Biological Sciences, The University of Tokyo, Tokyo 113-0033, Japan. \\ 2 Department of Integrated Genetics, National Institute of Genetics, Mishima, Shizuoka 411- \\ 8540, Japan. *Corresponding authors.
}

\begin{abstract}
Transposable elements (TEs) are robustly silenced by targeting of multiple epigenetic marks, but dynamics of crosstalk among these marks remains enigmatic. In Arabidopsis, TEs are silenced by cytosine methylation in both $\mathrm{CpG}$ and non-CpG contexts ( $\mathrm{mCG}$ and $\mathrm{mCH}$ ) and histone $\mathrm{H} 3$ lysine 9 methylation (H3K9me). While $\mathrm{mCH}$ and $\mathrm{H} 3 \mathrm{~K} 9 \mathrm{me}$ are mutually dependent for their maintenance, $\mathrm{mCG}$ and $\mathrm{mCH} / \mathrm{H} 3 \mathrm{~K} 9 \mathrm{me}$ are independently maintained. Here we show that establishment, rather than maintenance, of $\mathrm{mCH}$ depends on $\mathrm{mCG}$, accounting for the synergistic colocalization of these silent marks in TEs. When mCG is lost, establishment of $\mathrm{mCH}$ is abolished in TEs. $\mathrm{mCG}$ also guides $\mathrm{mCH}$ in active genes, although genic $\mathrm{mCH} / \mathrm{H} 3 \mathrm{~K} 9 \mathrm{me}$ is removed there. Unexpectedly, the targeting efficiency of $\mathrm{mCH}$ depends on relative, rather than absolute, levels of $\mathrm{mCG}$, suggesting underlying global negative controls. We propose that the local positive feedback in heterochromatin dynamics, together with global negative feedback, drive robust and balanced epigenome patterning.
\end{abstract}

\section{Introduction}

Large genomes of vertebrates and plants contain substantial amounts of transposable elements (TEs) and their derivatives. As TEs are a potential threat to genome 
stability and proper gene expression, they are silenced by epigenetic mechanisms such as cytosine methylation and histone $\mathrm{H} 3$ methylation at lysine $9(\mathrm{H} 3 \mathrm{~K} 9 \mathrm{me})^{1-4}$. In plant genomes, methylated cytosines are enriched in TEs for both $\mathrm{CpG}$ and non-CpG (or $\mathrm{CpH}$, where $\mathrm{H}$ can be $\mathrm{A}, \mathrm{T}$, or $\mathrm{C}$ ) contexts ${ }^{5,6}$. In Arabidopsis, methylation at $\mathrm{CpG}$ sites (mCG) is maintained by a DNA methyltransferase (MTase) called MET1 (METHYLTRANSFERASE 1) ${ }^{7,8}$. Methylation at $\mathrm{CpH}$ sites $(\mathrm{mCH})$ is catalyzed by another class of DNA MTases, CHROMOMETHYLASE 2 and $3\left(\mathrm{CMT} 2\right.$ and CMT3) ${ }^{9-12}$. These CMTs are recruited to regions with H3K9me. H3K9me is catalyzed by SUVH4, SUVH5 and SUVH6, and these H3K9 MTases, in turn, are recruited to regions with $\mathrm{mCH}^{10,13,14}$, generating a self-reinforcing positive feedback loop ${ }^{15}$. By this positive feedback, $\mathrm{mCH}$ and $\mathrm{H} 3 \mathrm{~K} 9$ me are maintained through cell divisions.

While $\mathrm{H} 3 \mathrm{~K} 9 \mathrm{me}$ and $\mathrm{mCH}$ depend on each other, their relationship to $\mathrm{mCG}$ has received less attention. Mutations in the CpG MTase gene MET1 have only minor effects on $\mathrm{mCH}$ and $\mathrm{H} 3 \mathrm{~K} 9 \mathrm{me}$; similarly, mutations in $\mathrm{CpH}$ MTases CMTs or H3K9 MTases SUVHs also have only minor effects on $\mathrm{mCG}^{5,6,13,16-18}$. Thus, these two layers of modifications are maintained largely independently.

Although the two layers of modifications, $\mathrm{mCG}$ and $\mathrm{mCH} / \mathrm{H} 3 \mathrm{~K} 9 \mathrm{me}$, are maintained independently, they are associated with each other during de novo establishment. This association in the establishment can be seen in both RNAi-dependent and -independent pathways. Plants can methylate both $\mathrm{CpG}$ and $\mathrm{CpH}$ sites in an RNAi-based pathway, called RdDM (RNA-directed DNA methylation). RdDM is a mechanism to trigger $\mathrm{mCG}$ and $\mathrm{mCH}$ by de novo DNA MTase DRM2, and its targeting depends on siRNAs and siRNA-associating RNAi components ${ }^{19,20}$. In addition to this well-investigated RNAi-based pathway, we have recently identified a very robust and precise RNAi-independent pathway to establish $\mathrm{mCH}$ and $\mathrm{H} 3 \mathrm{~K} 9$ me de novo in coding regions of TEs (TE genes); both $\mathrm{H} 3 \mathrm{~K} 9 \mathrm{me}$ and $\mathrm{mCH}$ are lost simultaneously in mutants for SUVHs or CMTs, but these marks recover efficiently and precisely in coding regions of TEs (TE genes) after reintroduction of the wild-type alleles ${ }^{18}$. 
Unexpectedly, this recovery of $\mathrm{mCH} / \mathrm{H} 3 \mathrm{~K} 9 \mathrm{me}$ is independent of the RNAi-based de novo DNA methylation machinery, such as DRM2 or RNA-dependent RNA polymerases. However, the recovery is inefficient in TE genes that lack $\mathrm{mCG}$. These results suggest that $\mathrm{mCG}$ might induce de novo establishment of $\mathrm{mCH}$ and $\mathrm{H} 3 \mathrm{~K} 9 \mathrm{me}$ in the RNAi-independent pathway.

Although both $\mathrm{mCG}$ and $\mathrm{mCH} / \mathrm{H} 3 \mathrm{~K} 9 \mathrm{me}$ are enriched in TEs, their distribution patterns differ in active genes. In addition to TEs, about $20 \%$ of active genes have mCG in their internal regions (gene bodies) ${ }^{21-24}$. In contrast, $\mathrm{mCH}$ and $\mathrm{H} 3 \mathrm{~K} 9 \mathrm{me}$ are found almost exclusively in $\mathrm{TEs}^{5,6}$. A factor contributing to the exclusion of $\mathrm{mCH} / \mathrm{H} 3 \mathrm{~K} 9 \mathrm{me}$ from active genes is a Jumonji domain-containing histone demethylase gene, INCREASE IN BONSAI METHYLATION 1 (IBM1) $25-27$; in ibm1 mutants, H3K9me and $\mathrm{mCH}$ accumulate in expressed genes. Interestingly, the genic $\mathrm{H} 3 \mathrm{~K} 9$ me and $\mathrm{mCH}$ in the $\mathrm{ibm} 1$ mutant background are found in genes with body $\mathrm{mCG}^{27}$. Thus, $\mathrm{mCG}$ might direct de novo $\mathrm{mCH}$ in genes, as well as in TEs. However, a causative link between $\mathrm{mCG}$ and $\mathrm{mCH} / \mathrm{H} 3 \mathrm{~K} 9 \mathrm{me}$ remains to be examined in both genes and TEs.

Here, we directly examined whether mCG is necessary for the establishment of $\mathrm{mCH}$ by using a mutation of $\mathrm{CpG}$ MTase gene MET1. The results revealed that TE genes that lose $\mathrm{mCG}$ by the met1 mutation failed to establish $\mathrm{mCH}$. In addition to the effect on TE genes, the met1-induced loss of $\mathrm{mCG}$ compromised genic $\mathrm{mCH}$ accumulating in the background of ibm1 mutant. Unexpectedly, the targeting efficiency of genic $\mathrm{mCH}$ depends on relative, rather than absolute, level of $\mathrm{mCG}$. Furthermore, genome-wide accumulation of genic $\mathrm{mCH}$ caused a global decrease of $\mathrm{mCH}$ in $\mathrm{TE}$ genes, suggesting global negative feedback in the heterochromatin dynamics. Based on these and previous results, we propose that global negative feedback and local positive feedback of heterochromatin marks, combined with $\mathrm{H} 3 \mathrm{~K} 9$ demethylation in active genes, results in robust and balanced differentiation of silent and active genomic regions. 


\section{Results}

\section{Loss of MET1 function abolishes establishment of $\mathrm{mCH}$ in TE genes}

Because $\mathrm{mCH}$ and $\mathrm{H} 3 \mathrm{~K} 9$ me depend on each other, both modifications are lost both in the $\mathrm{cmt} 2 \mathrm{cmt} 3$ double mutant of the $\mathrm{mCH}$ MTase genes (hereafter referred to as $c c$ ) and in the suvh4 suvh5 suvh6 triple mutant of the H3K9 MTase genes (hereafter referred to as sss). The $\mathrm{F} 1$ progeny between these mutants inherited genomes without $\mathrm{H} 3 \mathrm{~K} 9 \mathrm{me}$ and $\mathrm{mCH}$, but all these mutated genes (CMTs and SUVHs) are complemented by functional wild-type alleles in heterozygous states in the $\mathrm{F} 1$ (Fig. 1a) ${ }^{18}$. Within $\mathrm{mCH}$, symmetric $\mathrm{mCHG}$ and asymmetric $\mathrm{mCHH}$ are often analyzed separately, because their controls are different; mCHG is catalyzed by $\mathrm{CMT} 3$ and $\mathrm{CMT} 2$, while $\mathrm{mCHH}$ is catalyzed by $\mathrm{CMT} 2^{11,12}$. In the $\mathrm{F} 1$ progeny, $\mathrm{mCH}$ and $\mathrm{H} 3 \mathrm{~K} 9$ me recovers efficiently despite their absence in the parents (Fig. $1 \mathrm{a}, \mathrm{c}, \mathrm{i})^{18}$. This efficient recovery is independent of RNAi, but inefficient in TE genes that lack mCG at transcription start site (TSS) ${ }^{18}$.

To directly investigate the possible contribution of $\mathrm{mCG}$ to the establishment of $\mathrm{mCH}$, we conducted the same genetic experiments in the mutant background of CpG methyltransferase gene MET1 (Fig. 1b). We used the incomplete loss-of-function allele, met1-128, because the null allele of met1 mutants in combination with $\mathrm{mCH}$ mutants result in severe developmental defects and infertility ${ }^{29}$. We generated the met1-1 cmt2 cmt3 and the met1-1 suvh4 suvh5 suvh6 mutants (hereafter referred to as mcc and msss, respectively) and performed a genetic cross between them to obtain the F1 plants (hereafter we call them as $m F 1$; Fig. $1 \mathrm{~b}$ ), which can be compared to the original $\mathrm{F} 1$ plants between $c c$ and sss (Fig. 1a). In contrast to the efficient recovery of $\mathrm{mCH}$ in $\mathrm{F} 1$ in the wild-type MET1 background (Fig. 1c,d,i,j), the $m \mathrm{~F} 1$ plants showed severe defects in the restoration of $\mathrm{mCH}$ in TE genes for both CHG (Fig. 1e-h) and CHH (Fig. 1k-n)contexts. 


\section{Loss of $\mathrm{mCG}$ is associated with loss of $\mathrm{mCH}$ recovery}

Next, we examined if the failure of $\mathrm{mCH}$ recovery in the $\mathrm{mF} 1$ was associated with the loss of mCG. Because met1-1 is an incomplete loss-of-function allele, mCG remains in many, although not all, of TE genes ${ }^{28,30}$ (Supplementary Fig. 1a). Likewise, some TE genes kept $\mathrm{mCG}$ in the mcc, msss and the $m \mathrm{~F} 1$ (Supplementary Fig. 1a). Thus, we compared the residual $\mathrm{mCG}$ and the efficiency of $\mathrm{mCH}$ recovery in the $\mathrm{mF} 1$. Indeed, $\mathrm{mCH}$ recovery was found where $\mathrm{mCG}$ remains (Fig. 2a,b). The residual $\mathrm{mCG}$ of the TE genes in the $m \mathrm{~F} 1$ associated proportionally with their $\mathrm{mCH}$ recovery (Fig. 2c,d). TE genes with loss of $\mathrm{mCG}$ did not recover $\mathrm{mCH}$ (Fig. 2d), further demonstrating contribution of $\mathrm{mCG}$ to $\mathrm{mCH}$ establishment.

\section{Genic $\mathrm{mCH}$ is directed to regions with relatively high levels of $\mathrm{mCG}$}

Next, we asked if $\mathrm{mCG}$ in genes also affects their $\mathrm{mCH}$. In wild-type plants, $\mathrm{H} 3 \mathrm{~K} 9 \mathrm{me} 2$ and $\mathrm{mCH}$ are excluded from genes and that depends on the histone demethylase IBM1; in the ibm1 mutant, $\mathrm{H} 3 \mathrm{~K} 9 \mathrm{me} 2$ as well as $\mathrm{mCH}$ accumulate in genic regions ${ }^{25-27}$. Importantly, the genic $\mathrm{mCH}$ in the $i b m 1$ mutant correlates with the presence of $\mathrm{mCG}^{26,27}$. To see if $\mathrm{mCG}$ in gene bodies is responsible for the $\mathrm{mCH}$ in the $i b m 1$ background, we generated the double mutants of met1-1 and ibm1-4 (Fig. 3a, bottom left, met1 ibm1, hereafter referred to as mi) and examined the effect of the met1 mutation on ibm1-induced genic $\mathrm{mCH}$ accumulation. In both met1-1 and mi plants, genic mCG was drastically reduced, but they still had some residual mCG (Fig. 3b, top panel, Supplementary Fig. 1b and Supplementary Fig. 2). Unexpectedly, although the genic mCG is low in the mi mutant, a significant increase of genic mCH was detected (Fig. 3b, bottom panel and Supplementary Fig. 2). Nonetheless, the genic $\mathrm{mCH}$ in $\mathrm{mi}$ plants correlated with levels of their residual mCG (Fig. 3c-e), suggesting that the relative, rather than absolute, level of $\mathrm{mCG}$ is critical for the ectopic $\mathrm{mCH}$ in mi mutants. The spectrum of $\mathrm{mCH}$ and $\mathrm{mCG}$ in mi plants differed from that in ibm1 plants 
and the spectrum differed even between different $m i$ individuals (Supplementary Fig. 3a-c and Supplementary Fig. 4). Importantly, the genic $\mathrm{mCH}$ in each of mi plants correlated best to $\mathrm{mCG}$ level of the same plant but much less to those of the other plants (Fig. $3 f$ and Supplementary Fig. 3d), suggesting that targeting of $\mathrm{mCH}$ is controlled by $\mathrm{mCG}$, rather than other intrinsic properties of each gene.

\section{Association of genic $\mathrm{mCG}$ and $\mathrm{mCH}$ in epigenetic variant individuals}

$\mathrm{mCH}$ accumulated preferentially in genes with relatively high levels of $\mathrm{mCG}$ in $\mathrm{mi}$ as in ibm1 single mutant plants. Unexpectedly, however, the level of mCG required for the accumulation of $\mathrm{mCH}$ seems much lower in mi than that in $i b m 1 ; 0.1$ of $\mathrm{mCHG}$ was achieved when genes have about 0.04 of $\mathrm{mCG}$ level in $\mathrm{mi}$, while more than 0.3 of mCG level in ibm1 single mutant (Fig. 3d). One possible explanation for the difference is that it is attributable to the global reduction of $\mathrm{mCG}$ in met1 background; in other words, the accumulation of genic $\mathrm{mCH}$ in ibm1 mutant background may depend on the relative, rather than absolute, level of $\mathrm{mCG}$. If the relative amount of $\mathrm{mCG}$ is really critical for the $\mathrm{mCH}$, local loss of $\mathrm{mCG}$ is expected to show a more clear and strong effect. We next tested this hypothesis using materials with local and heritable loss of $\mathrm{mCG}$, as stated below.

In plants, variation in $\mathrm{mCG}$ patterns tend to be transmitted stably over generations ${ }^{31-}$ 34. That results in heritable loss of genic $\mathrm{mCG}$ detected among wild-type MET1/MET1 siblings in the progeny of MET1/met1 heterozygotes; and the spectrum of $\mathrm{mCG}$ loss is variable among individuals ${ }^{35,36}$. Consistent with these previous results, loss of genic mCG was detected in the MET1/MET1 ibm1/ibm1 plants (hereafter referred to as Mi) originated from MET1/met1-1 IBM1/ibm1 double-heterozygotes (Fig. 3a, bottom right and Supplementary Fig. 1c), and the spectrum of mCG differed among individual Mi plants (Fig. 4a). We used such heritable mCG variation among individuals to examine the association between local mCG loss and the ectopic $\mathrm{mCH}$ seen in the ibm1 mutants. 
In the two Mi siblings, genes with high $\mathrm{mCG}$ in only one of the two individuals (red and blue in Fig. 4a) show specific accumulation of $\mathrm{mCH}$ in that individual (Fig. 4b,c). In addition, genes with low mCG in both of the two individuals (green in Fig. 4a) show consistent lack of $\mathrm{mCH}$ accumulation (Fig. $4 \mathrm{~b}$ ). These results further demonstrate that genic $\mathrm{mCH}$ detected in the absence of IBM1 function depends on mCG.

\section{$\mathrm{mCH}$ is controlled not only locally but also globally}

The results above indicate that the relative, rather than the absolute, $\mathrm{mCG}$ level is critical for targeting of $\mathrm{mCH}$ seen in the $i b m 1$ mutant background. In other words, $\mathrm{mCH} / \mathrm{H} 3 \mathrm{~K} 9 \mathrm{me}$ is targeted to regions with $\mathrm{mCG}$, but this targeting seems much enhanced when $\mathrm{mCG}$ levels are low in the other regions of the genome. The $\mathrm{mCH}$ levels may be controlled by a global negative feedback mechanism, which would explain the significant genic $\mathrm{mCH}$ in mi plants despite its low $\mathrm{mCG}$.

In agreement with this interpretation, we have previously reported results suggesting global negative feedback to control heterochromatin marks, using another Arabidopsis mutant ddm1 (decrease in DNA methylation 1) ${ }^{11,37,38}$. The ddm1 mutation induces loss of $\mathrm{mCG}$ and $\mathrm{mCH}$ in heterochromatic TE genes ${ }^{11}$. The $d d m 1$-induced loss of $\mathrm{mC}$ in TEs is associated with ectopic and stochastic gain of $\mathrm{mC}$ in other loci including genic regions ${ }^{39,40 .}$ Importantly, from a cross between $d d m 1$ and wild-type plants, the progenies in wild-type $D D M 1$ plants show the ectopic methylation even in regions originated from wild-type DDM1 parent. This ectopic methylation correlates with amount of chromosome regions inherited from the $d d m 1$ parent, further demonstrating that loss of DNA methylation in TE genes induces genic $\mathrm{mCH}$ in trans ${ }^{40}$. The ectopic $\mathrm{mCH}$ is also induced in a met1 mutant ${ }^{32}$, consistent with the idea that global loss of $\mathrm{mCG}$ accelerates targeting of $\mathrm{mCH} / \mathrm{H} 3 \mathrm{~K} 9 \mathrm{me}$ machinery via a global negative feedback mechanism.

The $d d m 1$ mutation abolishes both $\mathrm{mCG}$ and $\mathrm{mCH}$. In addition to global $\mathrm{mCG}$, global 
$\mathrm{mCH}$ levels may also affect $\mathrm{mCH}$ pattern formation by negative feedback. Gain of genic $\mathrm{mCH}$ in $\mathrm{ibm} 1$ mutant induced reduction of $\mathrm{mCH}$ in $\mathrm{TE}$ genes (Fig. 5a). In the ibm1 mutant, the genic $\mathrm{mCH}$ accumulate progressively over generations ${ }^{40,41}$, and the reduction of $\mathrm{mCH}$ in TE genes in ibm1 was also progressive over generations (Fig. 5a), consistent with the idea that $\mathrm{mCH}$ levels are controlled globally by negative feedback. The genic $\mathrm{mCH}$ in $i b m 1$ mutation was much enhanced in the $d d m 1$ ibm1 double mutant (Fig. 5b,c), further suggesting that $\mathrm{mCH}$ levels are controlled by global negative feedback.

\section{Discussion}

In plant genomes, both $\mathrm{mCG}$ and $\mathrm{H} 3 \mathrm{~K} 9 \mathrm{me} 2 / \mathrm{mCH}$ are important for silencing TEs, and both are enriched in TEs. Paradoxically, however, these two layers of modifications are maintained almost independently. Here we showed that $\mathrm{mCG}$ directs establishment of $\mathrm{mCH}$, even though their maintenance is rather independent. Thus, we propose that colocalization of $\mathrm{mCG}$ and $\mathrm{mCH}$ in heterochromatin reflects this mechanistic link. Importantly, the very robust targeting of $\mathrm{mCH}$ we examined in this study is independent of RNAi for both TE genes $^{18}$ and active genes ${ }^{26}$.

In contrast, RNAi is involved in targeting of mCG. The dynamics of mCG has been examined after its loss in met1 mutation and reintroduction of a functional MET1 gene ${ }^{18,30,42}$. In those systems, TE genes with efficient $\mathrm{mCG}$ recovery are associated not only with $\mathrm{mCH}$ but also with siRNAs, suggesting that RNAi and/or $\mathrm{mCH}$ also enhance establishment of mCG. When methylation is lost in both contexts in the ddm1 mutants, the recovery is much slower than the cases in which methylation remains in one of the two contexts ${ }^{18,31,43}$. Thus, each of $\mathrm{mCH}$ and $\mathrm{mCG}$ facilitates establishment of the other.

RNAi-based mechanisms play especially significant part in non-coding regions of TEs ${ }^{11,18}$. siRNAs induce de novo DNA methylation by DRM2 ${ }^{19,20}$. DRM2, in turn, also affects siRNA formation ${ }^{44}$. Furthermore, it was recently shown that siRNAs direct H3K9me in a DRM- 
independent pathway ${ }^{45}$. The emerging view would be that the three layers of marks (mCG, $\mathrm{mCH} / \mathrm{H} 3 \mathrm{~K} 9 \mathrm{me}$, and siRNAs) interact locally to establish silent chromatin in both coding and non-coding regions (Fig. 6a). On the other hand, active chromatin states are stabilized by another positive feedback loop comprised of transcription and active H3K9 demethylation by IBM1 (Fig. 6a).

Although these multiple positive feedback mechanisms would stabilize and enhance silent and active states, positive feedback alone would have risk for the system to go out of control to excess. In addition to these local positive feedback mechanisms, our observation of $i b m 1$, met1, and ddm1 mutants revealed global negative feedback mechanisms to control genomic $\mathrm{mCH}$ level. Most significantly, global loss of $\mathrm{mCG}$ induces strong enhancement of machinery to direct $\mathrm{mCH}$ to regions with $\mathrm{mCG}$ (Fig. 3). In addition, $\mathrm{mCH}$ is also controlled negatively by global $\mathrm{mCH}$ level (Fig. 5a). Global negative feedback, combined with local positive feedback, would generate robust and balanced differentiation of active and silent genomic regions. The reaction-diffusion model is a powerful paradigm to understand pattern formation during development ${ }^{46}$, but that could also be applied to the pattern formation of active and inactive transcription units within the genome. The positive feedback mechanisms function locally to separate heterochromatic and euchromatic genomic domains, and the negative feedback by diffusible factor(s) controls the proportion of heterochromatic regions within the genome (Fig. 6b). Although the molecular basis for the global negative feedback remains unexplored, one possible mechanism could be a limitation of protein amounts involved in heterochromatin formation, such as CMTs and SUVHs.

Differentiation between genes and TE genes depends on histone demethylase IBM1 as well as on a chromatin remodeler DDM1; DDM1 is necessary for the TE-specific mCG, $\mathrm{mCH}$ and $\mathrm{H} 3 \mathrm{~K} 9 \mathrm{me}^{11,37,38,47}$, but the underlying mechanisms have remained enigmatic. It has recently been shown that DDM1 binds to heterochromatin-specific $\mathrm{H} 2 \mathrm{~A}$ variant $\mathrm{H} 2 \mathrm{~A} . \mathrm{W}$ and silence of TE genes in combination with H2A.W ${ }^{48}$. This pathway seems to be conserved in 
mammals; LSH1, the mammalian ortholog of DDM1, silences repetitive sequences by deposition of heterochromatin-specific $\mathrm{H} 2 \mathrm{~A}$ variant macro- $\mathrm{H} 2 \mathrm{~A}^{49}$. In Arabidopsis, another H2A variant, $H 2 A . Z$, negatively interacts with $\mathrm{mCG}^{18,41,50,51}$, and this pathway seems to be conserved to vertebrates ${ }^{23}$. Involvement of $\mathrm{H} 2 \mathrm{~A}$ variants in the local and global feedback mechanisms may also be an important target for future research.

\section{Methods}

\section{Plant materials and growth conditions}

The mutants met1-128, cc (cmt2 cmt3) ${ }^{11}$ and sss (suvh4 suvh5 suvh6) $)^{52}$ are kind gifts from Eric Richards, Daniel Zilberman and Judith Bender. The mutants mcc (met1-1 cmt2 cmt3), msss (met1-1 suvh4 suvh5 suvh6), mF1, mi (met1-1 ibm1-4), Mi (MET1 ibm14) and ddm1 ibm1 were made in this study. The homozygous mutants of met1-1 cmt2 cmt3 and met1-1 suvh4 suvh5 suvh6 were used for genetic crosses to create the $m \mathrm{~F} 1$ plants.

The plants were grown at $22^{\circ} \mathrm{C}(16 \mathrm{~h}$ light, $8 \mathrm{~h}$ dark), firstly on MS agar media for $1-$ 2 weeks and then grown on soil. $d d m 1 \mathrm{ibm} 1$ plants were grown on MS agar media until harvesting.

\section{Whole Genome Bisulfite Sequencing and data processing}

Genomic DNA was extracted from rosette leaves of one individual plant using the Nucleon Phytopure genomic DNA extraction kit (GE Healthcare), and whole genome bisulfite sequencing (WGBS) was performed as described previously ${ }^{18}$. Basically, two independent biological replicates were taken except for the wild-type Col-0, met1-1 and the second generation of ibm1-4 mutant. Genomic DNA was subjected to fragmentation using Focused Ultrasonicator (Covaris S220), and the size of 300-450bp were gel-extracted. The libraries were prepared using TruSeq DNA LT Sample Prep Kit (Illumina) and then subjected to bisulfite conversion using MethylCode Bisulfite Conversion Kit (Life Technologies). The 
resulting DNA were amplified using KAPA HiFi HotStart Uracil ReadyMix (Kapa Biosystems) and purified with Agencourt AMPure XP (Beckman Coulter). Raw sequence data and processed data were deposited in the GEO (GSE181896). The adaptor trimming and quality filtration were performed using Trimmomatic version $0.33^{53}$. The trimmed sequences were mapped to the Arabidopsis reference genome (TAIR10), deduplicated, and methylation data extracted using Bismark version 0.10.157

The annotations of genes and TEs are based on The Arabidopsis Information Resource $^{55}$. The details of the annotation of TE genes is in TAIR website (https://www.arabidopsis.org). We used Perl scripts ${ }^{18}$ to count the numbers of methylated and total cytosines within a gene, and the methylation level for each context of each gene were calculated as the number of methylated cytosine within a gene divided by the number of total cytosine (weighted methylation level ${ }^{56}$ ). Rstudio (v1.1.463) was used to create scatter plots, box plots, and sliding window analysis. Genome Browser (Integrated Genome Browser ${ }^{57}$ ) was used to for browser views. To create the heatmaps, TE genes and their surrounding regions ( $2 \mathrm{~kb}$ ) were divided into 20 and 10 segments respectively, then for each segment the value of methylated cytosines over total cytosines were calculated with Perl script. TE genes with the length $(<1000, n=1038)$ were excluded. The processed data were visualized using TreeView $3^{58}$. The methylation recovery rates show in Fig. $1 \mathrm{~h}$ and Fig. 1n, the methylation level of each gene in the $\mathrm{F} 1$ or $\mathrm{mF} 1$ were divided by that of corresponding background (WT or met1-1, respectively). To avoid division by values near zero, TE genes with low methylation level in WT and met1-1 (CHG $<0.1$ for Fig. $1 \mathrm{~h} ; \mathrm{n}=318$, or $\mathrm{CHH}<0.03$ for Fig. 1n; n=388) were excluded.

\section{Data availability}

WGBS data in this study were deposited in the GEO with the accession number GSE181896. All other reasonable requests for data and research materials are available via contacting 
the corresponding author.

\section{Competing Interest Statement}

The authors declare no competing interests.

\section{Acknowledgements}

We thank Eric Richards and Robert Schmitz for critical comments on the manuscript, and Judith Bender, Robert Fischer, Eric Richards and Daniel Zilberman for sharing mutant strains. Computations were partially performed on the NIG supercomputer at NIG, Japan. Supported by grants from, Japanese Ministry of Education, Culture, Sports, Science and Technology (26221105, $15 \mathrm{H} 0596319 \mathrm{H} 00995$ and $21 \mathrm{H} 04977$ to T.K., $19 \mathrm{H} 05740$ and 17K15059 to T.K.T.), CREST Grant, Japan (JPMJCR15O1 to T.K.), Systems Functional Genetics Project of the Transdisciplinary Research Integration Center, ROIS, Japan (to Y.T. and T.K.).

\section{Author Contributions}

T.K.T., C.Y., S.O. and T.K. designed the study. T.K.T., C.Y., S.O., S.T., A.K., Y.T. and T.K. performed the experiments. T.K.T., C.Y. and S.O. analyzed the data. T.K.T. and T.K. wrote the paper with incorporating comments from the other authors.

\section{References}

1. Saze, H. \& Kakutani, T. Differentiation of epigenetic modifications between transposons and genes. Curr. Opin. Plant Biol. 14, 81-87 (2011).

2. Kim, M.Y. \& Zilberman, D. DNA methylation as a system of plant genomic immunity. Trends Plant Sci. 19, 320-326 (2014). 
3. Du, J., Johnson, L.M., Jacobsen, S.E. \& Patel, D.J. DNA methylation pathways and their crosstalk with histone methylation. Nat. Rev. Mol. Cell Biol. 16, 519-532 (2015).

4. Underwood, C.J., Henderson, I.R. \& Martienssen, R.A. Genetic and epigenetic variation of transposable elements in Arabidopsis. Curr. Opin. Plant Biol. 36, 135-141 (2017).

5. Cokus, S.J. et al. Shotgun bisulphite sequencing of the Arabidopsis genome reveals DNA methylation patterning. Nature 452, 215-219 (2008).

6. Lister, R. et al. Highly integrated single-base resolution maps of the epigenome in Arabidopsis. Cell 133, 523-536 (2008).

7. Finnegan, E.J. \& Dennis, E.S. Isolation and identification by sequence homology of a putative cytosine methyltransferase from Arabidopsis thaliana. Nucleic Acids Res. 21, 2383-2388 (1993).

8. Finnegan, E.J., Peacock, W.J. \& Dennis, E.S. Reduced DNA methylation in Arabidopsis thaliana results in abnormal plant development. Proc. Natl Acad. Sci. USA 93, 8449-8454 (1996).

9. Bartee, L., Malagnac, F. \& Bender, J. Arabidopsis cmt3 chromomethylase mutations block non-CG methylation and silencing of an endogenous gene. Genes \& Dev. 15, 1753-1758 (2001).

10. Jackson, J.P., Lindroth, A.M., Cao, X. \& Jacobsen, S.E. Control of CpNpG DNA methylation by the KRYPTONITE histone H3 methyltransferase. Nature 416, 556-560 (2002).

11. Zemach, A. et al. The Arabidopsis nucleosome remodeler DDM1 allows DNA methyltransferases to access H1-containing heterochromatin. Cell 153, 193-205 (2013).

12. Stroud, H. et al. Non-CG methylation patterns shape the epigenetic landscape in Arabidopsis. Nat. Struct. Mol. Biol. 21, 64-72 (2014).

13. Malagnac, F., Bartee, L. \& Bender, J. An Arabidopsis SET domain protein required for maintenance but not establishment of DNA methylation. EMBO J. 21, 6842-6852 (2002). 
14. Du, J. et al. Dual binding of chromomethylase domains to H3K9me2-containing nucleosomes directs DNA methylation in plants. Cell 151, 167-180 (2012).

15. Johnson, L., Cao, X. \& Jacobsen, S. Interplay between two epigenetic marks. DNA methylation and histone H3 lysine 9 methylation. Curr. Biol. 12, 1360-1367 (2002).

16. Tariq, M. et al. Erasure of $\mathrm{CpG}$ methylation in Arabidopsis alters patterns of histone $\mathrm{H} 3$ methylation in heterochromatin. Proc. Natl Acad. Sci. USA 100, 8823-8827 (2003).

17. Deleris, A. et al. Loss of the DNA methyltransferase MET1 Induces H3K9 hypermethylation at PcG target genes and redistribution of H3K27 trimethylation to transposons in Arabidopsis thaliana. PLoS Genet. 8, e1003062 (2012).

18. To, T.K. et al. RNA interference-independent reprogramming of DNA methylation in Arabidopsis. Nat. Plants 6, 1455-1467 (2020).

19. Matzke, M.A. \& Mosher, R.A. RNA-directed DNA methylation: an epigenetic pathway of increasing complexity. Nat. Rev. Genet. 15, 394-408 (2014).

20. Cuerda-Gil, D. \& Slotkin, R.K. Non-canonical RNA-directed DNA methylation. Nat. Plants 2, 16163 (2016).

21. Zhang, X. et al. Genome-wide high-resolution mapping and functional analysis of DNA methylation in Arabidopsis. Cell 126, 1189-1201 (2006).

22. Zilberman, D., Gehring, M., Tran, R.K., Ballinger, T. \& Henikoff, S. Genome-wide analysis of Arabidopsis thaliana DNA methylation uncovers an interdependence between methylation and transcription. Nat. Genet. 39, 61-69 (2007). 
23. Zemach, A., McDaniel, I.E., Silva, P. \& Zilberman, D. Genome-wide evolutionary analysis of eukaryotic DNA methylation. Science 328, 916-919 (2010).

24. To,T.K., Saze, H. \& Kakutani, T. DNA methylation within transcribed regions. Plant Physiol. 168, 12191225 (2015).

25. Saze, H., Shiraishi, A., Miura, A. \& Kakutani, T. Control of genic DNA methylation by a jmjC domaincontaining protein in Arabidopsis thaliana. Science 319, 462-465 (2008).

26. Miura, A. et al. An Arabidopsis jmjC domain protein protects transcribed genes from DNA methylation at CHG sites. EMBO J. 28, 1078-1086 (2009).

27. Inagaki, S. et al. Autocatalytic differentiation of epigenetic modifications within the Arabidopsis genome. EMBO J. 29, 3496-3506 (2010).

28. Kankel, M.W. et al. Arabidopsis MET1 cytosine methyltransferase mutants. Genetics 163, 1109-1122 (2003).

29. Xiao, W. et al. DNA methylation is critical for Arabidopsis embryogenesis and seed viability. Plant Cell 18, 805-814 (2006).

30. Catoni, M. et al. DNA sequence properties that predict susceptibility to epiallelic switching. EMBO J. 36, 617-628 (2017).

31. Kakutani, T., Munakata, K., Richards, E.J. \& Hirochika, H. Meiotically and mitotically stable inheritance of DNA hypomethylation induced by ddm1 mutation of Arabidopsis thaliana. Genetics 151, 831-838 (1999).

32. Mathieu, O., Reinders, J., Caikovski, M., Smathajitt, C. \& Paszkowski, J. Transgenerational stability 
of the Arabidopsis epigenome is coordinated by CG methylation. Cell 130, 851-862 (2007).

33. Schmitz, R.J. et al. Transgenerational epigenetic instability is a source of novel methylation variants. Science 334, 369-373 (2011).

34. Gallego-Bartolomé, J. et al. Co-targeting RNA Polymerases IV and V Promotes Efficient De Novo DNA Methylation in Arabidopsis. Cell 176, 1068-1082.e19 (2019).

35. Saze, H., Mittelsten Scheid, O. \& Paszkowski, J. Maintenance of CpG methylation is essential for epigenetic inheritance during plant gametogenesis. Nat. Genet. 34, 65-69 (2003).

36. Stroud, H., Greenberg, M.V.C., Feng, S., Bernatavichute, Y.V. \& Jacobsen, S.E. Comprehensive analysis of silencing mutants reveals complex regulation of the Arabidopsis methylome. Cell 152, 352364 (2013).

37. Vongs, A., Kakutani, T., Martienssen, R.A. \& Richards, E.J. Arabidopsis thaliana DNA methylation mutants. Science 260, 1926-1928 (1993).

38. Jeddeloh, J.A., Stokes, T.L. \& Richards, E.J. Maintenance of genomic methylation requires a SWI2/SNF2-like protein. Nat. Genet. 22, 94-97 (1999).

39. Saze, H. \& Kakutani, T. Heritable epigenetic mutation of a transposon-flanked Arabidopsis gene due to lack of the chromatin-remodeling factor DDM1. EMBO J. 26, 3641-3652 (2007).

40. Ito, T. et al. Genome-wide negative feedback drives transgenerational DNA methylation dynamics in Arabidopsis. PLoS Genet. 11, e1005154 (2015).

41. Coleman-Derr, D. \& Zilberman, D. Deposition of histone variant H2A.Z within gene bodies regulates responsive genes. PLoS Genet. 8, e1002988 (2012). 
42. Rigal, M., et al. Epigenome confrontation triggers immediate reprogramming of DNA methylation and transposon silencing in Arabidopsis thaliana F1 epihybrids. Proc. Natl Acad. Sci. USA 113, E2083-2092 (2016).

43. Teixeira, F.K. et al. A role for RNAi in the selective correction of DNA methylation defects. Science 323, 1600-1604 (2009).

44. Zilberman, D. et al. Role of Arabidopsis ARGONAUTE4 in RNA-directed DNA methylation triggered by inverted repeats. Curr. Biol. 14, 1214-1220 (2004).

45. Parent, J.S., Cahn, J., Herridge, R.P., Grimanelli, D. \& Martienssen, R.A. Small RNAs guide histone methylation in Arabidopsis embryos. Genes \& Dev. 35, 841-846 (2021).

46. Kondo, S. \& Miura, T. Reaction-diffusion model as a framework for understanding biological pattern formation. Science 329, 1616-1620 (2010).

47. Gendrel, A.V., Lippman, Z., Yordan, C., Colot, V. \& Martienssen, R.A. Dependence of heterochromatic histone H3 methylation patterns on the Arabidopsis gene DDM1. Science 297, 1871-1873 (2002).

48. Osakabe, A. et al. The chromatin remodeler DDM1 prevents transposon mobility through deposition of histone variant H2A.W. Nat. Cell Biol. 23, 391-400 (2021).

49. Ni, K. et al. LSH mediates gene repression through macroH2A deposition. Nat. Commun. 11, 5647 (2020).

50. Zilberman, D., Coleman-Derr, D., Ballinger, T. \& Henikoff, S. Histone H2A.Z and DNA methylation are mutually antagonistic chromatin marks. Nature 456, 125-129 (2008). 
51. Nie, W.F. et al. Histone acetylation recruits the SWR1 complex to regulate active DNA demethylation in Arabidopsis. Proc. Natl Acad. Sci. USA 116, 16641-16650 (2019).

52. Ebbs, M.L. \& Bender, J. Locus-specific control of DNA methylation by the Arabidopsis SUVH5 histone methyltransferase. Plant Cell 18, 1166-1176 (2006).

53. Bolger, A.M., Lohse, M. \& Usadel, B. Trimmomatic: a flexible trimmer for Illumina sequence data. Bioinformatics 30, 2114-2120 (2014).

54. Krueger, F. \& Andrews, S.R. Bismark: a flexible aligner and methylation caller for Bisulfite-Seq applications. Bioinformatics 27, 1571-1572 (2011).

55. Lamesch, P. et al. The Arabidopsis Information Resource (TAIR): improved gene annotation and new tools. Nucleic Acids Res. 40, D1202-1210 (2012).

56. Schultz, M.D., Schmitz, R.J. \& Ecker, J.R. 'Leveling' the playing field for analyses of single-base resolution DNA methylomes. Trends Genet. 28, 583-585 (2012).

57. Nicol, J.W., Helt, G.A., Blanchard, S.G. Jr., Raja, A. \& Loraine, A.E. The Integrated Genome Browser: free software for distribution and exploration of genome-scale datasets. Bioinformatics 25, 2730-2731 (2009).

58. Keil, C. et al. Treeview 3.0 (beta 1) - Visualization and analysis of large data matrices. Zenodo $1303402(2018)$. 


\section{To_Fig.1}

a

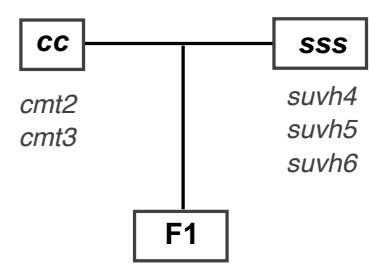

Heterozygous for the five mutations in CMT and SUVH genes. b

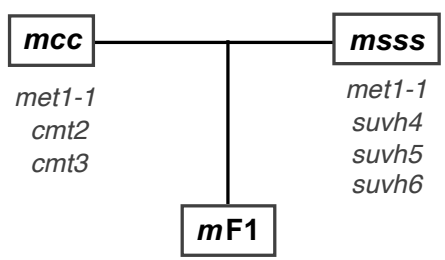

Heterozugous for the mutations in CMT and SUVH genes in homozygous met1-1 mutant background

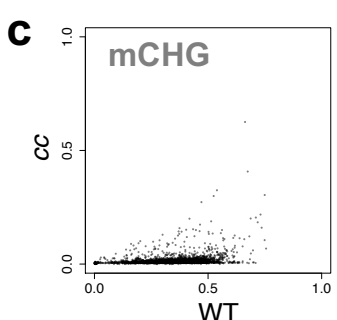

e
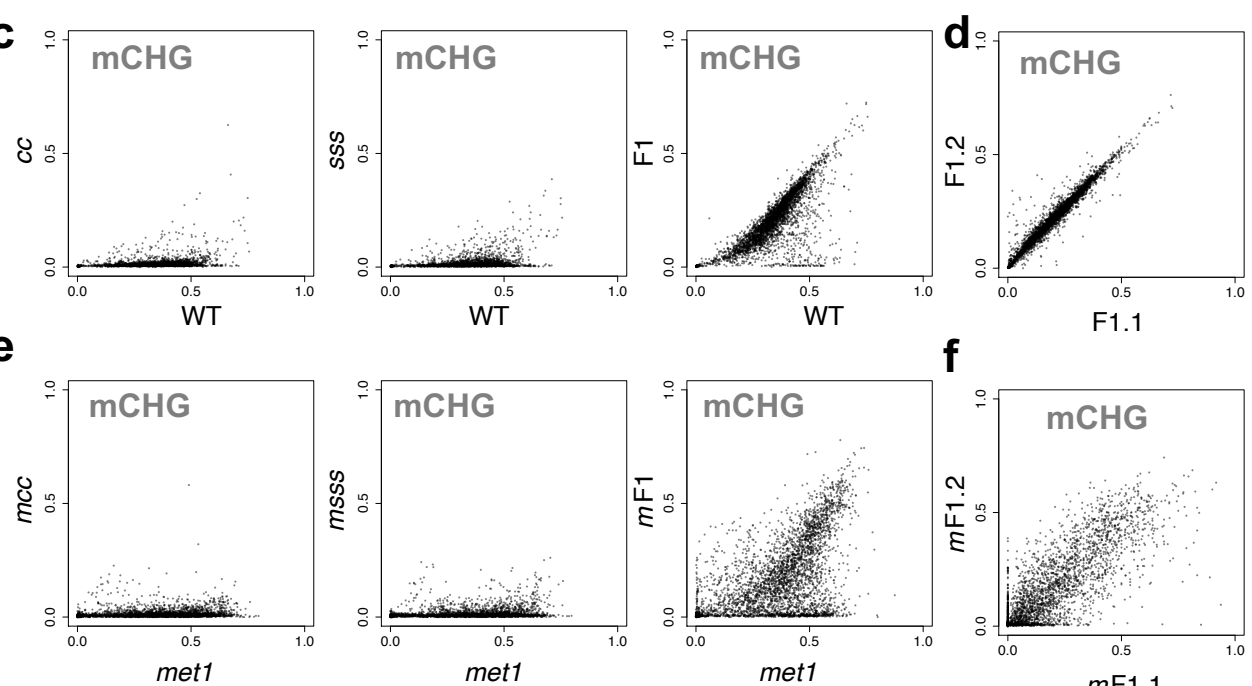

f
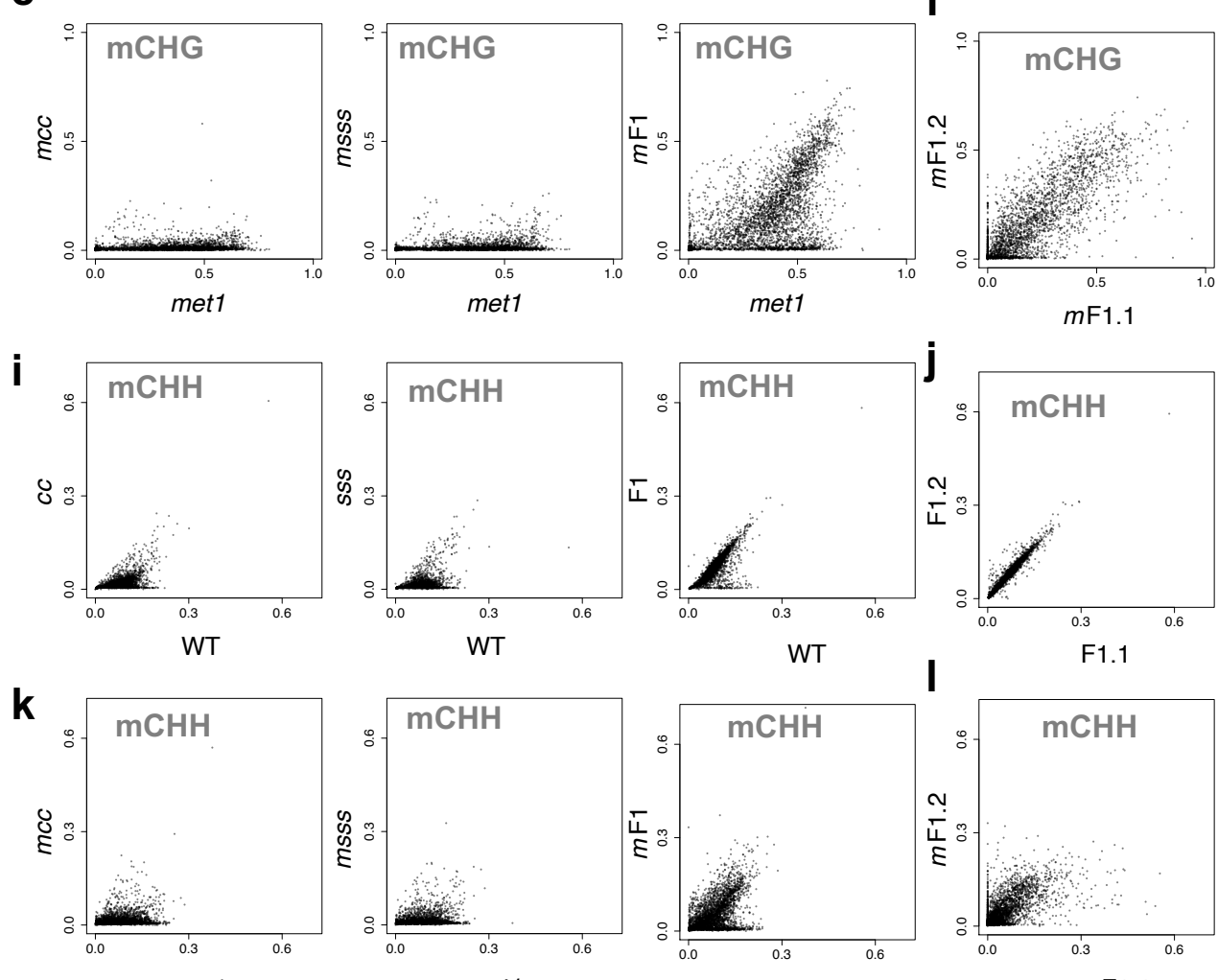

met1

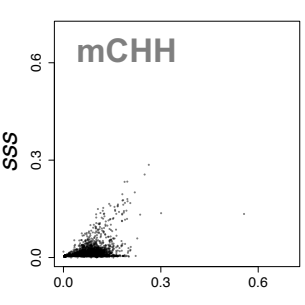

WT
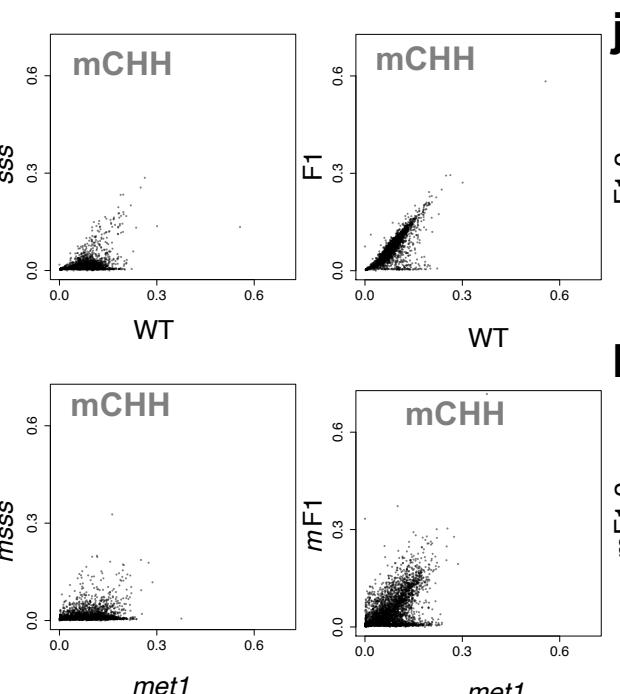

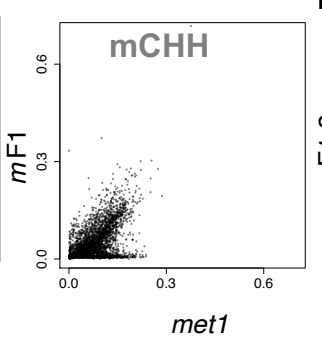

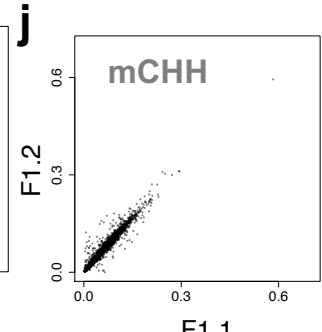

F1.1

I

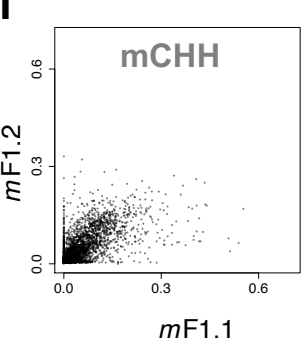

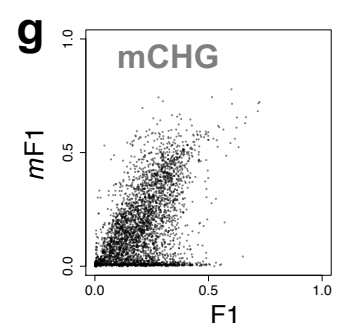

h
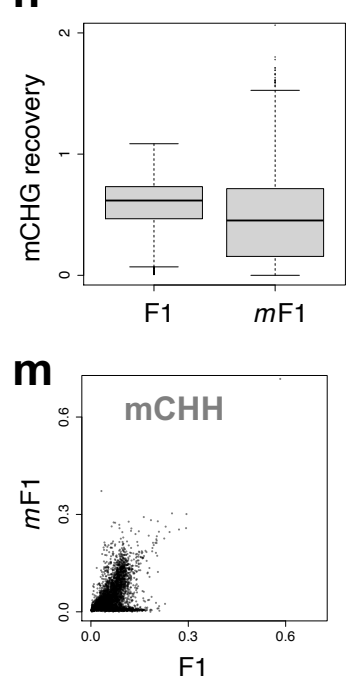

n

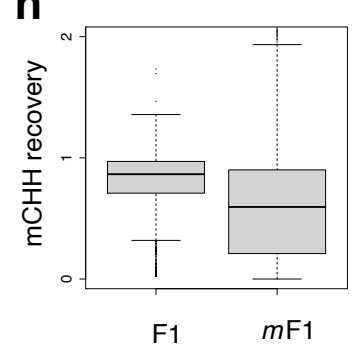




\section{Fig. 1 Loss of MET1 function abolishes establishment of $\mathrm{mCH}$ in TE genes.}

a, b Scheme of genetic crosses. Mutant of CpH MTases (cmt2 cmt3 : cc) and mutant of H3K9 MTases (suvh4 suvh5 suvh6 : sss) were crossed to generate F1, which are heterozygous for all the mutated genes (a). Analogous cross was done between F0 of met1-1 mutant background ( $m c c$ and $m s s s$ ) to generate F1 with homozygous met1-1 mutation $(m \mathrm{~F} 1)(\mathbf{b}) . \mathbf{c} \mathrm{mCHG}$ recovery in the $\mathrm{F} 1 . \mathrm{mCHG}$ level of each TE gene in the mutants, cc (left), sss (middle), and the F1 (right), compared to a wild-type plant (WT). The results are reproduction of published results (GSE148753 ${ }^{18}$ ). d A comparison of $\mathrm{mCHG}$ between the two individual $\mathrm{F} 1$ plants. e $\mathrm{mCHG}$ recovery in the $m \mathrm{~F} 1 . \mathrm{mCHG}$ level of each $\mathrm{TE}$ gene in the mutants mcc (left), msss (middle), and the $m \mathrm{~F} 1$ (right), compared to a met1-1 mutant. $\mathbf{f}$ A comparison of $\mathrm{mCHG}$ between the two individual $m \mathrm{~F} 1$ plants. $\mathbf{g}$ A comparison of $\mathrm{mCHG}$ level between the $\mathrm{F} 1$ and $m \mathrm{~F} 1$ plants. $\mathbf{h}$ The efficiency of $\mathrm{mCHG}$ recovery in $\mathrm{F} 1$ and $m \mathrm{~F} 1$ plants. The efficiency of recovery was calculated as F1 / WT and $m \mathrm{~F} 1$ / met1, respectively. To avoid division by values near zero, TE genes with $\mathrm{mCHG}(>0.1)$ in both WT and met1 mutant were used $(n=3212)$. Outliers deviated from the panel are not shown $(n=11)$. $\mathbf{i}-\mathbf{m}$ $\mathrm{mCHH}$ recovery of TE genes in the $\mathrm{F} 1$ and $m \mathrm{~F} 1$ in the format of $(\mathbf{c})-(\mathbf{g})$, respectively. $\mathbf{n}$ The efficiency of $\mathrm{mCHH}$ recovery in $\mathrm{F} 1$ and $m \mathrm{~F} 1$ plants. The efficiency of recovery was calculated as F1 / WT and $m \mathrm{~F} 1$ / met1, respectively. To avoid division by values near zero, TE genes with $\mathrm{mCHH}(>0.03)$ in both WT and met1 mutant were used in $(\mathbf{n})(\mathrm{n}=2915)$. Outliers deviated from the panel are not shown $(\mathrm{n}=40)$. The original data for WT, $c c$, sss and F1 are from GSE148753 ${ }^{18}$. 


\section{To_Fig.2}

a

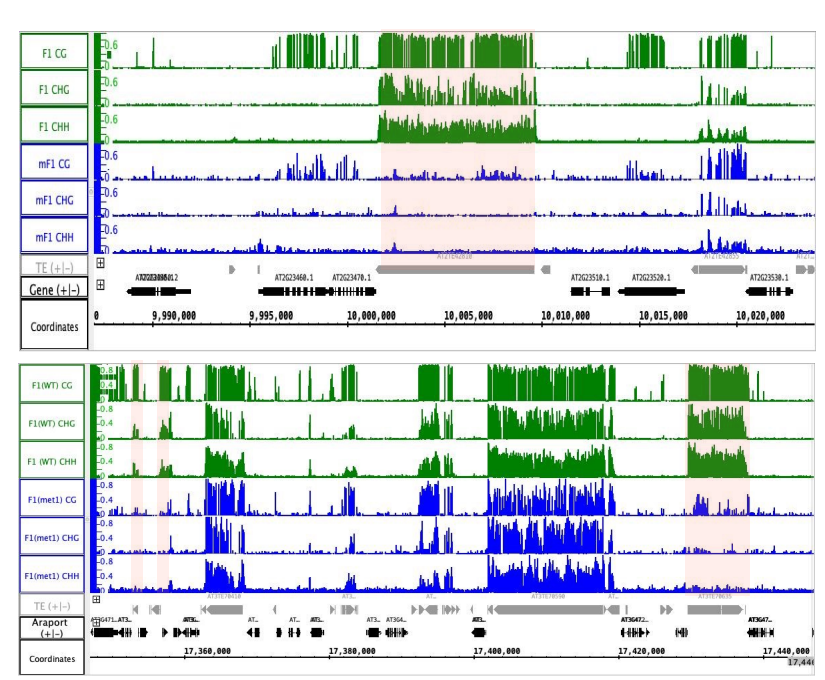

b
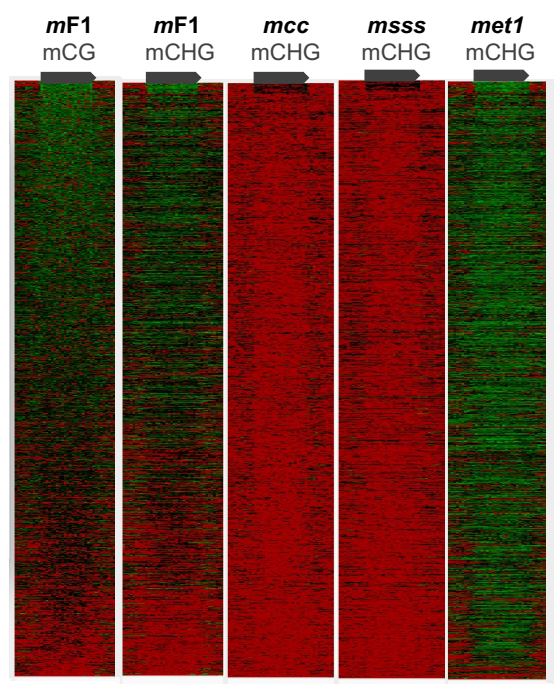

WT $\mathrm{mCHG}$

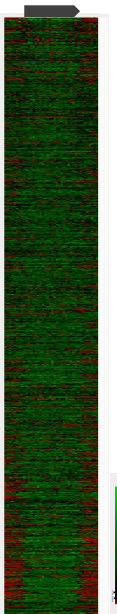

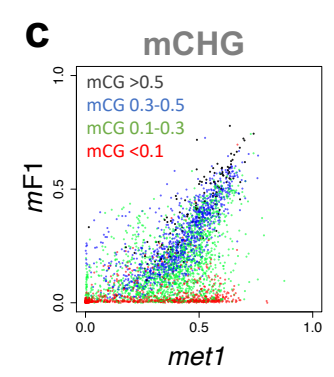
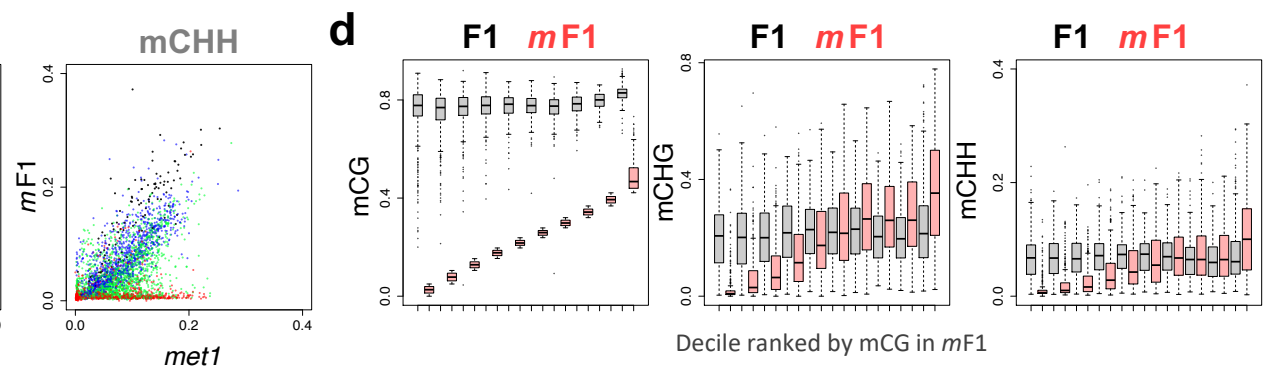

Decile ranked by $\mathrm{mCG}$ in $m \mathrm{~F} 1$

Fig. 2 Loss of $\mathrm{mCG}$ is associated with loss of $\mathrm{mCH}$ recovery.

a Genome Browser view of $\mathrm{mCG}, \mathrm{mCHG}$ and $\mathrm{mCHH}$ in $\mathrm{F} 1$ and $m \mathrm{~F} 1$ plants. TEs with loss of $\mathrm{mCG}$ fail to restore $\mathrm{mCH}$ in $\mathrm{mF} 1$ (highlighted in pink). The regions of $\mathrm{Chr} / 9,987,000-$ 10,024,000 (upper) and Chr1/16,420,326-16,439,454 (lower) are shown. Grey and black arrows represent TEs and genes, respectively. $\mathbf{b} \mathrm{mCHG}$ recovers in TE genes with remaining $\mathrm{mCG}$. Each TE gene (length> 1000; $\mathrm{n}=2422$ ) is aligned according to the $\mathrm{mCG}$ levels in $m \mathrm{~F} 1$ and the methylation levels are shown in the form of heatmap for each genotype. Grey arrows represent TE genes. c Recovery of $\mathrm{mCHG}$ (left) and $\mathrm{mCHH}$ (right) is associated with the residual $m C G$ in $m F 1$. The scatter plots shown in the right panel of Fig. 1e and Fig. $1 \mathrm{k}$ were colored according to the residual $\mathrm{mCG}$ in $m \mathrm{~F} 1$. Red : $<0.1$, green : $0.1-0.3$, blue : $0.3-0.5$, and black : $>0.5$ for $\mathrm{mCG}$ in $m \mathrm{~F} 1$. 


\section{(Fig.2 continued)}

d Boxplots showing the association between the residual $\mathrm{mCG}$ and $\mathrm{mCH}$ recovery in $m \mathrm{~F} 1$. TE genes are divided into deciles according to the $\mathrm{mCG}$ levels in $m \mathrm{~F} 1$, and their $\mathrm{mCG}$ (left), $\mathrm{mCHG}$ (middle) and $\mathrm{mCHH}$ (right) levels in $\mathrm{F} 1$ and $m \mathrm{~F} 1$ plants are shown. TE genes with $\mathrm{mCHG}(>0.1)$ in both WT and met1-1 were analyzed $(n=3200) . X$ axis represents $\mathrm{mCG}$ levels in $m \mathrm{~F} 1$ divided into deciles and ordered from lower to higher. Each horizontal black line represents the median. 
a

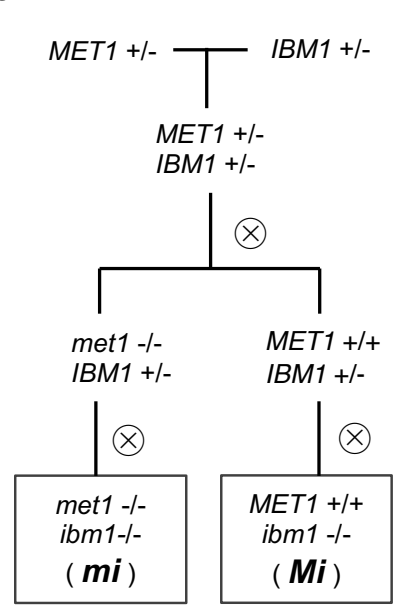

e

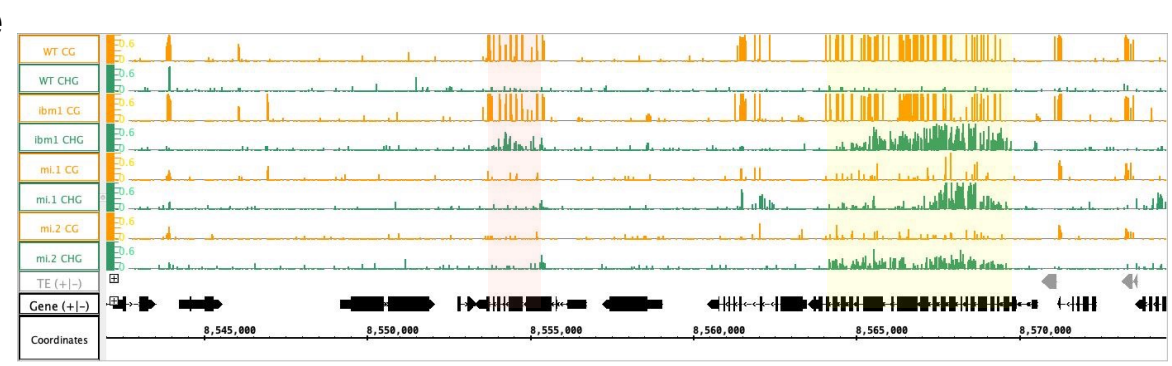

b

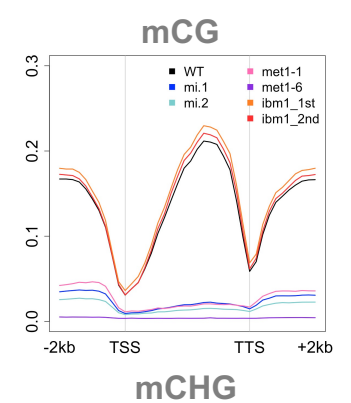

C

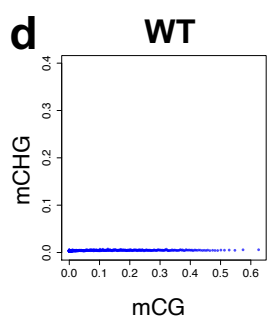

To_Fig.3
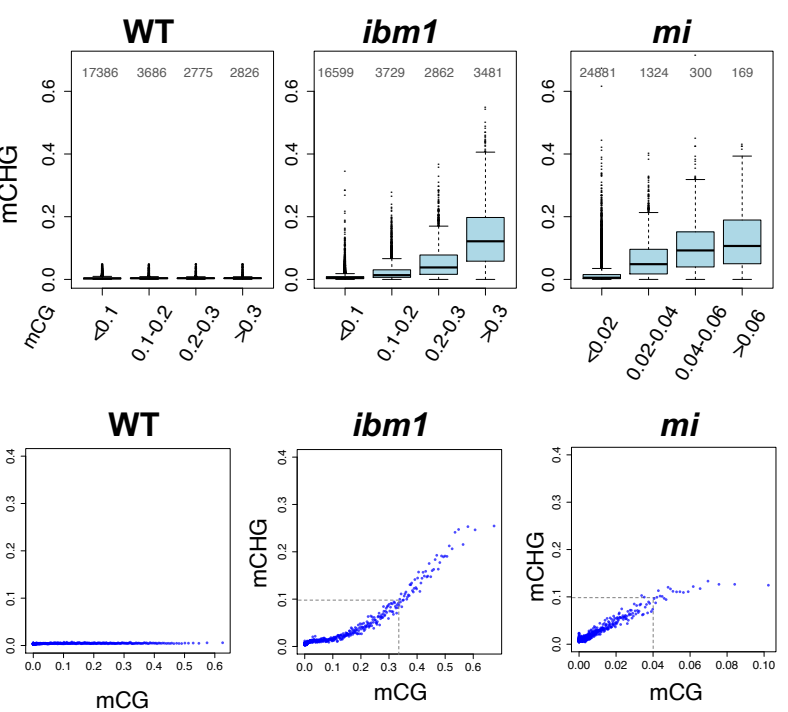

f

$\mathrm{mCG}$

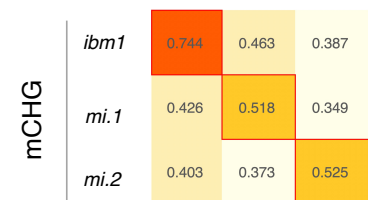

Fig. 3 Genic $\mathrm{mCH}$ is directed to regions with relatively high levels of $\mathrm{mCG}$.

a Materials used. Starting from the cross between plants having met1-1 (met1) or ibm1-4 (ibm1) mutation in heterozygous state, the double heterozygote was self-pollinated to fix met1 homozygote and MET1 wild-type in the F2 generation. The ibm1 mutation was fixed to be homozygous in the F3 generation. The F3 plants with homozygous met1-1 mutation (mi) and homozygous wild-type MET1 (Mi) were used in this study. b Averaged mCG and mCHG profiles over genes in a WT plant, ibm1, met1 ibm1 (mi) and met1 mutants. Values for met1-6, a null mutant of MET1, are shown for comparison (GSE148753). c mCHG levels are correlated with the mCG levels in both $i b m 1$ and $m i$. Genes are divided according to the mCG levels in the indicated genotypes and corresponding $\mathrm{mCHG}$ levels are shown by boxplots. The number of genes in each class is shown on the top. 


\section{(Fig. 3 continued)}

d The genes were sorted by the mCG levels of indicated genotypes, grouped in bins with 50 genes, and averaged $\mathrm{mCHG}$ levels in the bins are plotted against averaged mCG levels in the corresponding bins. Mean value is plotted for each bin. e Browser view of mCG (orange) and $\mathrm{mCHG}$ (green) in $\mathrm{WT}$, ibm1, and two individual mi mutants. The region of Chr1/8,542,000-8,574,500 is shown. Grey and black arrows represent TEs and genes, respectively. Yellow shadow indicates an example of genic $\mathrm{mCHG}$ commonly seen in ibm1 and mi mutants. It has residual mCG in the mi plants. Pink shadow indicates an example of genic $\mathrm{mCHG}$ seen in ibm1 but not in mi mutants. $\mathbf{f}$ Correlation analysis of $\mathrm{mCHG}$ and $\mathrm{mCG}$ in the ibm1 and two mi individual plants. The best correlated in the individuals are boxed in red. The number in the box represents the Pearson's correlation coefficient. To exclude misannotated TEs, the genes with $\mathrm{mCHG}$ in the WT $(>0.05)$ are excluded from the analysis in panels $\mathbf{b}-\mathbf{d}$ and $\mathbf{f}$ (excluded $n=1562 ;$ analyzed $n=26723)$. 

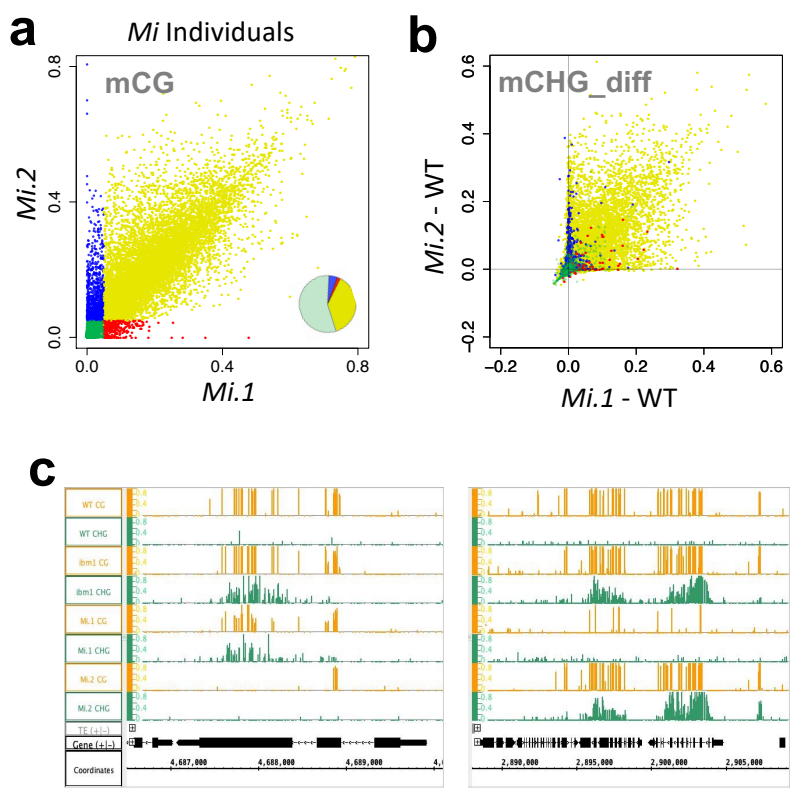

Fig. 4 Association of genic $\mathrm{mCG}$ and $\mathrm{mCH}$ in epigenetic variant individuals.

a Differential mCG levels of genes in the two Mi individuals. The genes with the mCG presence $(>0.05)$ or absence $(<0.05)$ in the individuals are colored in yellow (commonly CG methylated), green (commonly CG hypomethylated), red (CG methylated only in Mi.1 individual) and blue (CG methylated only in Mi.2 individual). The ratio of each group was shown as pie chart in the right bottom. $\mathbf{b}$ The increase in genic $\mathrm{mCHG}$ in the Mi individuals. The genes are colored according to the groups in (a). c Browser view of representative variable ectopic $\mathrm{mCHG}$ in $\mathrm{Mi}$ individuals. The gene in the left panel shows ectopic $\mathrm{mCHG}$ in $i b m 1$ and Mi.1 but not in Mi.2. The genes in the right panel show genic $\mathrm{mCHG}$ in $i b m 1$ and Mi.2 but not in Mi.1. The regions of Chr5/4,686,500-4,690,100 (left) and Chr1/2,888,0002,906,200 (right) are shown. Grey and black arrows below represent TEs and genes, respectively. To exclude the mis-annotated TEs, the genes with $\mathrm{mCHG}$ in the WT $(>0.05)$ are excluded from the analysis in $(\mathbf{a}, \mathbf{b})$ (excluded $n=1562$; analyzed $n=26723$ ). 

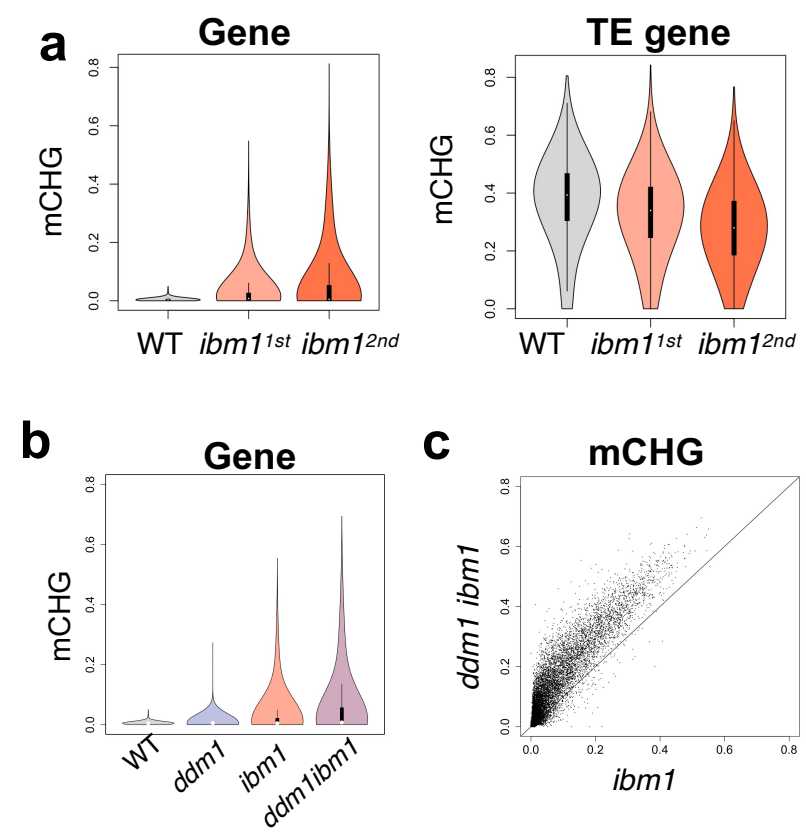

Fig. $5 \mathrm{mCH}$ is controlled not only locally but also globally.

a Violin plots showing the progressive accumulation of $\mathrm{mCHG}$ in genes and decrease of mCHG in TE genes in the $i b m 1$ mutant. b Violin plot showing that $d d m 1$ mutation further enhanced the ibm1-induced accumulation of $\mathrm{mCHG}$ in genes. c The ibm1-induced genic $\mathrm{mCHG}$ was globally enhanced in $d d m 1 \mathrm{ibm} 1$ double mutant (line: $\mathrm{y}=\mathrm{x}$ ). 
a Local positive feedback

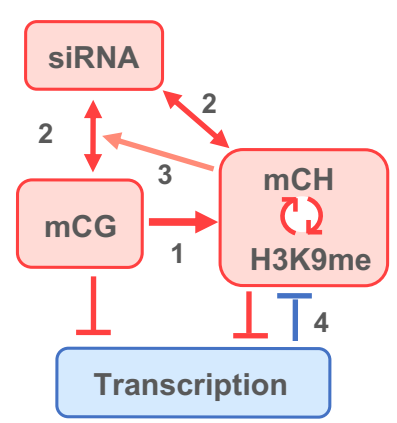

b Global negative feedback
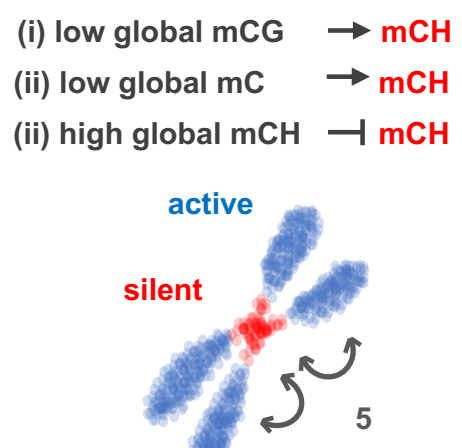

Fig. 6 Local positive feedback and global negative feedback drive epigenome patterning.

a Integrated model of local chromatin differentiation in Arabidopsis. (1) mCG directs precise and efficient de novo establishment of $\mathrm{mCH} / \mathrm{H} 3 \mathrm{~K} 9 \mathrm{me}$ in $\mathrm{RNAi}$-independent pathway (This study and To et al. $2020^{18}$ ). (2) siRNA directs $\mathrm{mCG}$ and $\mathrm{mCH}$ by DRM2. In addition, DRM affects siRNA ${ }^{44}$. Furthermore, siRNA directs H3K9me in DRM2-independent pathway ${ }^{45}$. (3) $\mathrm{mCH} / \mathrm{H} 3 \mathrm{~K} 9 \mathrm{me}$ enhances siRNA-directed de novo $\mathrm{mCG}^{18,30}$. (4) Transcription induces demethylation of $\mathrm{H} 3 \mathrm{~K} 9 \mathrm{me}$ by histone demethylase IBM127. b A model for global negative feedback. In this model, we propose that the machinery to target $\mathrm{mCH} / \mathrm{H} 3 \mathrm{~K} 9 \mathrm{me}$ is negatively regulated by global level of $\mathrm{mCG}$ and $\mathrm{mCH} / \mathrm{H} 3 \mathrm{~K} 9 \mathrm{me}$. The proposal is based on our three observations: (i) genic $\mathrm{mCH}$ is directed to regions with relatively high level of $\mathrm{mCG}$, and this pathway is enhanced when global level of $\mathrm{mCG}$ is low (in $\mathrm{mi}$ in Fig. 3); (ii) when mCG and $\mathrm{mCH}$ of TEs decrease globally in the $d d m 1$ mutant, ectopic $\mathrm{mCH}$ is induced in genes ${ }^{40}$, and this increase is further enhanced in $d d m 1 \mathrm{ibm} 1$ mutant (Fig. 5 b,c); (iii) when genic mCH increases in the ibm1 mutant, $\mathrm{mCH}$ in TE decreases (Fig. 5a). By this global negative feedback, amount of heterochromatin would not go to extreme, despite the strong local positive feedback mechanisms (a), resulting in balanced differentiation of active and silent chromosomal domains (5). 